\title{
The Serum Changes of Neuron-Specific Enolase and Intercellular Adhesion Molecule-1 in Patients With Diffuse Axonal Injury Following Progesterone Administration: A Randomized Clinical Trial
}

\author{
Nader Shahrokhi, ${ }^{1}$ Zahra Soltani, ${ }^{2,}{ }^{*}$ Mohammad Khaksari, ${ }^{3}$ Saeid Karamouzian, ${ }^{4}$ Behshad Mofid, ${ }^{4}$ and \\ Gholamreza Asadikaram ${ }^{5}$ \\ ${ }^{1}$ Physiology Research Center, Institute of Neuropharmacology, Afzalipour School of Medicine, Kerman University of Medical Sciences, Kerman, IR Iran \\ ${ }^{2}$ Endocrinology and Metabolism Research Center, Institute of Basic and Clinical Physiology Sciences, Kerman University of Medical Sciences, Kerman, IR Iran \\ ${ }^{3}$ Neuroscience Research Center, Institute of Neuropharmacology, Kerman University of Medical Sciences, Kerman, IR Iran \\ ${ }^{4}$ Department of Neurosurgery, Kerman University of Medical Sciences, Kerman, IR Iran \\ ${ }^{5}$ Department of Biochemistry, Kerman University of Medical Sciences, Kerman, IR Iran \\ "Corresponding author: Zahra Soltani, Endocrinology and Metabolism Research Center, Institute of Basic and Clinical Physiology Sciences, Kerman University of Medical \\ Sciences, Kerman, IR Iran. Tel: +98-3433257581, Fax: +98-3433257581, E-mail: soltaniy@yahoo.com
}

Received 2016 February 09; Revised 2016 May 02; Accepted 2016 May 10.

\begin{abstract}
Background: Improvement of neurologic outcome in progesterone-administered patients with diffuse axonal injury (DAI) has been found in a recent study. Also, there has been interest in the importance of serum parameters as predictors of outcome in traumatic brain injury.

Objectives: The aim of this study was to examine the effect of progesterone administration on serum levels of neuron-specific enolase (NSE), and intercellular adhesion molecule-1 (ICAM-1) in clinical DAI.

Patients and Methods: In this study, the serum levels of ICAM-1 and NSE of 32 male DAI patients (18 - 60 years of age, a Glasgow coma scale of 12 or less, and admitted within 4 hours after injury) who were randomized for a controlled phase II trial of progesterone were analyzed. The analysis was performed between the control and progesterone groups at admission time, and 24 hours and six days after DAI, respectively.

Results: A reduction in the serum level of ICAM-1 was noticed in the progesterone group 24 hours after the injury $(\mathrm{P}<0.05)$. There was no significant difference in the serum level of NSE between the study groups during evaluation. At 24 hours after the injury, the level of ICAM-1 in the control group was higher than that at admission time $(\mathrm{P}<0.05)$. The lowest level of NSE in the two groups was seen six days after DAI $(\mathrm{P}<0.01)$.

Conclusions: In summary, progesterone administration reduced serum ICAM-1, and whereby may attenuate blood brain barrier disruption, the latter needs further investigation for confirmation.
\end{abstract}

Keywords: Intercellular Adhesion Molecule-1, Neuron-Specific Enolase, Progesterone, Serum, Diffuse Axonal Injury

\section{Background}

Traumatic brain injury (TBI) is a major cause of death and disability (1), and there are no currently treatments that improve clinical outcome (2). Progesterone as a reproduction-related hormone exerts anti-oxidative, antiapoptotic, and anti-inflammatory effects in the nervous system (3). Experimental studies have suggested that progesterone is a promising neuroprotective agent in TBI (4$6)$, but analyses of phase III clinical trials with progesterone have not been shown to be successful on functional outcome $(7,8)$. This failure may be due to the lack of evaluating biomarkers relevant to TBI (9). Thus, the evaluation of serum markers may help the diagnosis of improvement following an intervention in a minimally invasive manner. The search for predictive markers of outcome in TBI has been begun over 20 years ago. The evaluation of biomarkers in TBI patients could help the intervention selection, and provide the prognostic information (1).

Pathophysiology of TBI is a complex interplay of brain specific proteins, and cytokine-mediated immune reactions (10). Inflammation has a great role in the pathophysiology of TBI (11). Interleukin-1 $\beta$ (IL-1 $\beta$ ), tumor necrosis factor (TNF- $\alpha$ ), and IL-6, which are released within minutes of the primary injury, can cause the infiltration of inflammatory cells into the brain by activating intercellular adhesion molecule-1 (ICAM-1) (12). It has been shown 
that cerebrospinal fluid (CSF) concentration of ICAM-1 indicates tissue and blood-brain barrier (BBB) damage, giving an indication of the immunologic reaction in the injured brain (13). Also, the increase in serum neuron-specific enolase (NSE) correlates with the injury of neurons (14). The neuron-specific enolase is one of its five isoenzymes of glycolytic enolase (15) and involved during the onset of neuronal activity. The neuron-specific enolase can be useful as a serum biomarker in diffuse axonal injury (DAI) (14).

The inhibition of ICAM-1 expression in the injured brain has been revealed by progesterone administration at five days after experimental TBI (16). Progesterone administration led to decreasing ICAM-1 expression at 48 hours after subarachnoid hemorrhage (SAH) (17). Progesterone treatment attenuated significantly markers of neuroinflammation in TBI rats, concomitant with reduction in neurologic impairments (18).

In our previous study, progesterone-administered DAI patients showed decreasing IL-1 $\beta$, and increasing IL- 6 and transforming growth factor- $\beta 1$ (TGF- $\beta 1$ ) in serum. Also, the serum level of malondialdehyde (MDA), as an indication of lipid peroxidation was reduced in them (19). However, the neuroprotective effect of progesterone on serum levels of NSE and ICAM-1 has not been investigated in clinical trial.

\section{Objectives}

The present study aimed to examine the effect of progesterone administration on serum levels of NSE and ICAM-1 in DAI patients of a randomized controlled phase II trial of progesterone. We hypothesized that modulating the pathophysiological pathways related to cerebral inflammation after TBI by progesterone is a mechanism whereby progesterone protects neurons, and improves neurologic outcome after TBI.

\section{Patients and Methods}

\subsection{The Study Patients}

This study was part of a single-center blinded, randomized, controlled phase II trial of progesterone that a part of the results of trial has been published (19). The approval of the trial protocol was obtained from the ethics committee of Kerman University of Medical Sciences (K/92/579) prior to the commencement of the trial. The trial was registered in Iranian registry of clinical trials (www.irct.ir, CT2014042017356N1). The eligibility criteria of trial were male, Glasgow coma scale (GCS) of 12 or less, pure DAI using a computed tomography (CT) scan, admission within four hours after injury, and 18 to 60 years of age. The patients of trial were randomly placed in either the case (received progesterone) or control group. The trial was executed in trauma center of Kerman province.

The case group received progesterone intramuscularly $1 \mathrm{mg} / \mathrm{kg} / 12$ hours for five days. All of the study patients received the standard management protocol for TBI (19).

Blood samples obtained at three time points (admission, and 24 hours and six days after the study) were analyzed to measure the ICAM-1 and NSE levels (19).

\subsection{The Measurement of Serum Levels of Intercellular Adhesion Molecule-1 and Neuron-Specific Enolase}

The serum levels of ICAM-1 (sensitivity range 31.3-2000 $\mathrm{pg} / \mathrm{mL}, \mathrm{R}$ and D) and NSE (sensitivity range $0.31-20 \mathrm{ng} / \mathrm{mL}$, $\mathrm{R}$ and $\mathrm{D}$ ) were assessed using commercially available enzyme- linked immunosorbent assay (ELISA) kits. Briefly, a quantitative assay of these variables was done using the secondary antibody labeled with peroxidase and producing colored product to read in a spectrophotometer. Astandard curve was prepared for any biomarker using respective standards, and the serum levels of biomarkers were determined using the respective standard curve. The serum levels of ICAM-1 and NSE were expressed as picograms per milliliter $(\mathrm{pg} / \mathrm{mL})$ and nanograms per milliliter $(\mathrm{ng} / \mathrm{mL})$, respectively.

\subsection{Statistical Analysis}

The data were expressed as mean \pm SEM. SPSS 20 software was used to analyze data. The data normality was checked by Shapiro-Wilk's test. The comparison of the variables among the times was performed using two-way repeated measures ANOVA. The comparison between the two groups was performed by two independent t-tests. A value of $\mathrm{P}<0.05$ was considered to be statistically significant.

\section{Results}

\subsection{The Study Patients}

No significant difference was found regarding age, injury time to randomization, severity of injury and cause of DAI between the two groups (Table 1).

4.2. The Serum Level of Intercellular Adhesion Molecule-1 in Diffuse Axonal Injury Patients Following Progesterone Administration

The effect of progesterone on the serum level of ICAM1 in DAI patients has shown in Table 2. No significant difference was found in the ICAM-1 level between the control and progesterone groups at the time of admission and six days after injury ( $\mathrm{P}=0.21$ and $\mathrm{P}=0.77$, respectively). In contrast, 24 hours after the injury, the ICAM-1 level was reduced in the progesterone group $(868.97 \pm 166.54 \mathrm{pg} / \mathrm{mL})$ 
Table 1. The Clinical and Demographic Characteristics of the Study Groups at the Admission Time

\begin{tabular}{|c|c|c|c|}
\hline Characteristics & Control $(n=16)$ & Progesterone $(n=16)$ & P Value \\
\hline Age, y; mean \pm SEM & $30.75 \pm 3.4$ & $28.44 \pm 1.74$ & 0.84 \\
\hline Injury time to randomization (minute); mean \pm SEM & $84.81 \pm 9.93$ & $69.36 \pm 19.38$ & 0.98 \\
\hline \multicolumn{4}{|l|}{ GCS (score); mean \pm SEM } \\
\hline Total & $7.75 \pm 0.52$ & $7.5 \pm 0.55$ & 0.81 \\
\hline Cause of DAI, No. (\%) & & & $\mathrm{N} / \mathrm{S}$ \\
\hline Motor vehicle & $15(93.8)$ & $16(100)$ & \\
\hline Fall & $0(0.0)$ & $0(0.0)$ & \\
\hline Other & $1(6.2)$ & $0(0.0)$ & \\
\hline
\end{tabular}

Abbreviations: DAI, diffuse axonal injury; GCS, Glasgow coma scale; N/S, not significant; n, number of patients.

compared to the control group (1422.96 $\pm 203.87 \mathrm{pg} / \mathrm{mL})$ $(\mathrm{P}<0.05)$. The amount of reduction in the progesterone group in comparison with the control group was 38.95\% at 24 hours after the injury. An increase in the ICAM-1 level was found in the control group at 24 hours in comparison to the admission time $(\mathrm{P}<0.05)$.

Table 2. The Effect of Progesterone on the Serum Level of Intercellular Adhesion Molecule-1 $(\mathrm{pg} / \mathrm{mL})$ in Diffuse Axonal Injury Patients

\begin{tabular}{|c|c|c|c|}
\hline Times & $\begin{array}{c}\text { Control }(\mathbf{n}=16) \\
\text { mean } \pm \text { SEM,pg } / \\
\mathbf{m L}\end{array}$ & $\begin{array}{c}\text { Progesterone }(n= \\
\text { 16) } \text { mean } \pm \text { SEM, } \\
\mathrm{pg} / \mathrm{mL}\end{array}$ & P Value \\
\hline Admission time & $829.47 \pm 93.31$ & $990.52 \pm 83.2$ & 0.21 \\
\hline $\begin{array}{l}24 \text { hours after } \\
\text { injury }\end{array}$ & $1422.96 \pm 203.87^{\mathrm{a}}$ & $868.97 \pm 166.54^{\mathrm{b}}$ & 0.04 \\
\hline $\begin{array}{l}6 \text { days after } \\
\text { injury }\end{array}$ & $865.81 \pm 193.61$ & $939.61 \pm 151.55$ & 0.77 \\
\hline
\end{tabular}

4.3. The Serum Level of Neuron-Specific Enolase in Diffuse Axonal Injury Patients Following Progesterone Administration

The effect of progesterone on the serum level of NSE in DAI patients has shown in Table 3. No significant difference was found in the NSE level between the control and progesterone groups during assay $(\mathrm{P}=0.42, \mathrm{P}=0.58$ and $\mathrm{P}=0.1$, respectively). A significant decrease was found in the NSE level in the control and progesterone groups six days after the injury in comparison to admission and $24 \mathrm{~h}$ after the injury $(\mathrm{P}<0.01)$.

\section{Discussion}

To our knowledge, the current study is the first study to examine the effect of progesterone administration on the
Table 3. The Effect of Progesterone on the Serum Level of Neuron-Specific Enolase $(\mathrm{ng} / \mathrm{mL})$ in Diffuse Axonal Injury Patients

\begin{tabular}{lcc}
\hline Times & $\begin{array}{c}\text { Control }(\mathbf{n}=\mathbf{1 6}) \text { mean } \\
\pm \text { SEM, ng/ml }\end{array}$ & $\begin{array}{c}\text { Progesterone }(\mathbf{n}=\mathbf{1 6}) \\
\text { mean } \pm \text { SEM, ng/ml }\end{array}$ \\
\hline Admission time & $15.41 \pm 0.85$ & $14.42 \pm 0.88$ \\
24 hours after injury & $14.83 \pm 0.87$ & $14.09 \pm 0.99$ \\
6 days after injury & $2.14 \pm 0.21^{\mathrm{a}, \mathrm{b}}$ & $5.63 \pm 1.67^{\mathrm{a}, \mathrm{b}}$ \\
\hline $\begin{array}{l}{ }^{\mathrm{a}} \mathrm{P}<0.01 \text { vs. admission in the control or progesterone group. } \\
{ }^{\mathrm{b}} \mathrm{P}<0.01 \text { vs. 24 hours after injury in the control or progesterone group. }\end{array}$
\end{tabular}

serum levels of ICAM-1 and NSE in DAI patients. The main findings of this study were: 1 , the serum level of ICAM-1 reduced remarkably in DAI patients following progesterone administration $24 \mathrm{~h}$ after injury; 2, progesterone did not change the serum level of NSE in DAI patients during evaluation.

The authors of this study have begun to examine the effect of progesterone as a therapeutic agent in clinical DAI by trying to account for their experimental studies $(4,5)$. They have reported that progesterone administration can cause the improvement of neurologic outcome in DAI patients (19).

Brain-related proteins are appeared in the systemic circulation following BBB disruption (20). Serum biomarkers in TBI are a useful means for evaluating the condition (21). Also, the assessment of TBI biomarkers improves the development of an individualized treatment (1). Studies have consistently demonstrated that progesterone, as a neurosteroid with multiple functions, modulates diverse secondary injury mechanisms in TBI, including apoptotic pathways, diffuse axonal injury, stress oxidative $(4,22)$, and the expression of inflammatory cytokines $(3,17)$. We have previously reported decreasing S100 calcium-binding protein B (S-100 B), IL-1 $\beta$ and MDA and increasing TGF- $\beta 1$ 
and IL-6 in serum associated to improving neurologic outcome in progesterone-administered DAI patients (19). In the present study, the effect of progesterone administration on the serum levels of ICAM-1 and NSE in DAI patients was determined.

In current study, the serum level of ICAM-1 reached to peak 24 hours after DAI and returned to the control level 6 days after DAI. Progesterone prevented the increase in ICAM-1 24 hours after DAI. The expression of IL-1 $\beta$, TNF- $\alpha$ and IL-6, and ICAM-1 in the injured brain up-regulates in TBI $(16,17)$. Activated astrocytes and microglia release a number of pro-inflammatory mediators that could contribute to secondary phase brain injury (23). Neuroinflammatory factors increase after TBI and likely contribute to oxidative stress and neuronal death, which in turn further exacerbate the inflammatory response (24). The BBB destruction in TBI is associated with serum level of ICAM-1 (25).

The effect of progesterone on the serum level of ICAM1 in the present study is consistent with studies that the ICAM-1 reduced in rats with brain injury following progesterone $(16,17)$. Also, progesterone decreased the inflammatory response and the leukocytes infiltration in the ischemic brain by inhibiting the expression of ICAM-1 (26). To the best of our knowledge, there has not yet been any contrary study assessing the effect of progesterone on ICAM-1 level in brain injury. The results of previous (19) and present studies confirm that a high level of adhesion molecules in TBI patients is associated with poor outcome (27).

In the current study, progesterone treatment did not alter the serum level of NSE that may be due to a number of reasons including dose and duration of the progesterone treatment or not targeted these parameters by progesterone that requires further exploration. To the best of our knowledge, there has not yet been any study assessing the effect of progesterone on the NSE level in brain injury. The increase in the NSE concentration could be an indication of inflammatory response after TBI (28). The relation of the NSE level in serum with outcome has been shown in $72 \mathrm{~h}$ postinjury, probably because of its short half-life (29). The increase in the serum level of NSE was associated to favorable outcome in other study (30). However, previous (19) and present studies indicate that the serum level of NSE is not different between patients with favorable outcome and those with unfavorable outcome. It is postulated that the difference between results may be due to the timing schedule used for taking blood samples. Also, in a study, early elevation in the CSF level of NSE in patients with severe TBI was able to predict those patients who would involve to brain death from those who would survive (31). It is mentioned that injury severity of the patients in our study was not severe.
Progesterone may act on inflammation both directly (32) and indirectly by the modulation of toll-like receptors and NF- $\kappa \mathrm{B}$ signaling with a concurrent reduction in cytokines (33). NF- $\kappa \mathrm{B}$ is a transcriptional factor required for the gene expression of many inflammatory mediators, such as IL-1 $\beta$, IL- 6 and ICAM-1 (17). The inhibition of NF-kB activation may provide a pharmacological agent against the pathological inflammatory conditions (34). The downregulation of NF-kB has been reported by progesterone at 5 days postinjury (16). So, progesterone may decrease ICAM1 by suppressing the NF-kB activation. The exact mechanisms remain unclear.

Therefore, progesterone may attenuate the development of secondary brain damage following primary trauma in part by decreasing ICAM-1. The latter may be one of the anti-inflammatory mechanisms of progesterone that needs further investigations for confirmation. An association of ICAM-1 and NSE to neurologic outcome in DAI also needs to be further studied.

\subsection{Limitations}

Our study has a number of limitations that should be considered. First, sample size of the study was small that can cause type II error. Second, the current study was limited to adults, whereas the TBI is also a very common occurrence in pediatric patients.

\section{Acknowledgments}

The authors are grateful to Dr. Elham Jafari in Kerman Shaheed Bahonar Hospital, Kerman University of Medical Sciences, for her management in collecting serum samples of the patients.

\section{Footnotes}

Authors' Contribution: Zahra Soltani and Behshad Mofid collected data and drafted the manuscript; Nader Shahrokhi and Saeid Karamouzian designed the trial; Mohammad Khaksari supervised the trial; Gholamreza Asadikaram managed the biochemical tests.

Funding/Support: We would like to thank the managers of physiology and neuroscience research centers of Kerman University of Medical Sciences, Prof. Najafipour and Prof. Sheibani, for their financial support.

\section{References}

1. Forde CT, Karri SK, Young AM, Ogilvy CS. Predictive markers in traumatic brain injury: opportunities for a serum biosignature. $\mathrm{Br} \mathrm{J} \mathrm{Neu-}$ rosurg. 2014;28(1):8-15. doi: 10.3109/02688697.2013.815317. [PubMed: 23855389]. 
2. McKee JA, Brewer RP, Macy GE, Borel CO, Reynolds JD, Warner DS. Magnesium neuroprotection is limited in humans with acute brain injury. Neurocrit Care. 2005;2(3):342-51. doi: 10.1385/NCC:2:3:342. [PubMed: 16159086].

3. De Nicola AF, Gonzalez Deniselle MC, Garay L, Meyer M, GargiuloMonachelli G, Guennoun R, et al. Progesterone protective effects in neurodegeneration and neuroinflammation. J Neuroendocrinol. 2013;25(11):1095-103. doi:10.1111/jne.12043. [PubMed: 23639063].

4. Shahrokhi N, Haddad MK, Joukar S, Shabani M, Keshavarzi Z, Shahozehi B. Neuroprotective antioxidant effect of sex steroid hormones in traumatic brain injury. PakJ Pharm Sci. 2012;25(1):219-25. [PubMed: 22186333].

5. Shahrokhi N, Khaksari M, Soltani Z, Mahmoodi M, Nakhaee N. Effect of sex steroid hormones on brain edema, intracranial pressure, and neurologic outcomes after traumatic brain injury. Can J Physiol Pharmacol. 2010;88(4):414-21. doi: 10.1139/y09-126. [PubMed: 20555409].

6. Stein DG. Is progesterone a worthy candidate as a novel therapy for traumatic brain injury?. Dialogues Clin Neurosci. 2011;13(3):352-9. [PubMed: 22033509].

7. Skolnick BE, Maas AI, Narayan RK, van der Hoop RG, MacAllister T, Ward JD, et al. A clinical trial of progesterone for severe traumatic brain injury. N Engl J Med. 2014;371(26):2467-76. doi: 10.1056/NEJMoa1411090. [PubMed: 25493978].

8. Wright DW, Yeatts SD, Silbergleit R, Palesch YY, Hertzberg VS, Frankel $\mathrm{M}$, et al. Very early administration of progesterone for acute traumatic brain injury. NEngl JMed. 2014;371(26):2457-66. doi:10.1056/NEJMoa1404304. [PubMed: 25493974].

9. Stein DG. Embracing failure: What the Phase III progesterone studies can teach about TBI clinical trials. Brain Inj. 2015;29(11):1259-72. [PubMed: 26274493].

10. Woodcock T, Morganti-Kossmann MC. The role of markers of inflammation in traumatic brain injury. Front Neurol. 2013;4:18. doi: 10.3389/fneur.2013.00018. [PubMed: 23459929].

11. Morganti-Kossmann MC, Rancan M, Otto VI, Stahel PF, Kossmann T. Role of cerebral inflammation after traumatic brain injury: a revisited concept. Shock. 2001;16(3):165-77. [PubMed: 11531017].

12. Carlos TM, Clark RS, Franicola-Higgins D, Schiding JK, Kochanek PM. Expression of endothelial adhesion molecules and recruitment of neutrophils after traumatic brain injury in rats. J Leukoc Biol. 1997;61(3):279-85. [PubMed: 9060450].

13. Pleines UE, Stover JF, Kossmann T, Trentz O, Morganti-Kossmann MC. Soluble ICAM-1 in CSF coincides with the extent of cerebral damage in patients with severe traumatic brain injury. $J$ Neurotrauma. 1998;15(6):399-409. doi: 10.1089/neu.1998.15.399. [PubMed: 9624625].

14. Kovesdi E, Luckl J, Bukovics P, Farkas O, Pal J, Czeiter E, et al. Update on protein biomarkers in traumatic brain injury with emphasis on clinical use in adults and pediatrics. Acta Neurochir(Wien). 2010;152(1):1-17. doi:10.1007/s00701-009-0463-6. [PubMed:19652904].

15. Cooper EH. Neuron-specific enolase. Int J Biol Markers. 1994;9(4):20510. [PubMed: 7836797].

16. Chen G, Shi J, Jin W, Wang L, Xie W, Sun J, et al. Progesterone administration modulates TLRs/NF-kappaB signaling pathway in rat brain after cortical contusion. Ann Clin Lab Sci. 2008;38(1):65-74. [PubMed: 18316784].

17. Wang Z, Zuo G, Shi XY, Zhang J, Fang Q, Chen G. Progesterone administration modulates cortical TLR4/NF-kappaB signaling pathway after subarachnoid hemorrhage in male rats. Mediators Inflamm. 2011;2011:848309. doi: 10.1155/2011/848309. [PubMed: 21403869].

18. Webster KM, Wright DK, Sun M, Semple BD, Ozturk E, Stein DG, et al. Progesterone treatment reduces neuroinflammation, oxidative stress and brain damage and improves long-term outcomes in a rat model of repeated mild traumatic brain injury. J Neuroinflammation. 2015;12:238. doi: 10.1186/s12974-015-0457-7. [PubMed: 26683475].

19. Mofid B, Soltani Z, Khaksari M, Shahrokhi N, Nakhaee N, Karamouzian $\mathrm{S}$, et al. What are the progesterone-induced changes of the outcome and the serum markers of injury, oxidant activity and inflammation in diffuse axonal injury patients?. Int Immunopharmacol. 2016;32:10310. doi: 10.1016/j.intimp.2016.01.015. [PubMed: 26803522].

20. Raabe A, Grolms C, Seifert V. Serum markers of brain damage and outcome prediction in patients after severe head injury. Br J Neurosurg. 1999;13(1):56-9. [PubMed: 10492686].

21. Moher D, Hopewell S, Schulz KF, Montori V, Gotzsche PC, Devereaux PJ, et al. CONSORT 2010 Explanation and Elaboration: Updated guidelines for reporting parallel group randomised trials. J Clin Epidemiol. 2010;63(8):e1-37. doi:10.1016/j.jclinepi.2010.03.004. [PubMed: 20346624].

22. Barha CK, Ishrat T, Epp JR, Galea LA, Stein DG. Progesterone treatment normalizes the levels of cell proliferation and cell death in the dentate gyrus of the hippocampus after traumatic brain injury. Exp Neurol. 2011;231(1):72-81. doi: 10.1016/j.expneurol.2011.05.016. [PubMed: 21684276].

23. Morganti-Kossmann MC, Satgunaseelan L, Bye N, Kossmann T. Modulation of immune response by head injury. Injury. 2007;38(12):1392400. doi: 10.1016/j.injury.2007.10.005. [PubMed: 18048036].

24. Abdul-Muneer PM, Chandra N, Haorah J. Interactions of oxidative stress and neurovascular inflammation in the pathogenesis of traumatic brain injury. Mol Neurobiol. 2015;51(3):966-79. doi: 10.1007/s12035-014-8752-3. [PubMed: 24865512].

25. Feuerstein GZ, Wang X, Barone FC. Inflammatory gene expression in cerebral ischemia and trauma. Potential new therapeutic targets. Ann NYAcad Sci. 1997;825:179-93. [PubMed: 9369986].

26. Wang J, Zhao Y, Liu C, Jiang C, Zhao C, Zhu Z. Progesterone inhibits inflammatory response pathways after permanent middle cerebral artery occlusion in rats. Mol Med Rep. 2011;4(2):319-24. doi: 10.3892/mmr.2011.418. [PubMed: 21468571].

27. Kirchhoff C, Buhmann S, Bogner V, Stegmaier J, Leidel BA, Braunstein $\mathrm{V}$, et al. Cerebrospinal IL-10 concentration is elevated in non-survivors as compared to survivors after severe traumatic brain injury. EurJMed Res. 2008;13(10):464-8. [PubMed: 19008173].

28. Pleines UE, Morganti-Kossmann MC, Rancan M, Joller H, Trentz O, Kossmann T. S-100 beta reflects the extent of injury and outcome, whereas neuronal specific enolase is a better indicator of neuroinflammation in patients with severe traumatic brain injury. J Neurotrauma. 2001;18(5):491-8. doi: 10.1089/089771501300227297. [PubMed: 11393252].

29. Schaarschmidt H, Prange HW, Reiber H. Neuron-specific enolase concentrations in blood as a prognostic parameter in cerebrovascular diseases. Stroke. 1994;25(3):558-65. [PubMed: 8128507].

30. Raheja A, Sinha S, Samson N, Bhoi S, Subramanian A, Sharma $P$, et al. Serum biomarkers as predictors of long-term outcome in severe traumatic brain injury: analysis from a randomized placebo-controlled Phase II clinical trial. J Neurosurg. 2016:1-11. doi: 10.3171/2015.6.JNS15674. [PubMed: 26722854].

31. Bohmer AE, Oses JP, Schmidt AP, Peron CS, Krebs CL, Oppitz PP, et al. Neuron-specific enolase, S100B, and glial fibrillary acidic protein levels as outcome predictors in patients with severe traumatic brain injury. Neurosurgery. 2011;68(6):1624-30. doi: 10.1227/NEU.ob013e318214a81f. [PubMed: 21368691] discussion 1630-1.

32. Cai J, Cao S, Chen J, Yan F, Chen G, Dai Y. Progesterone alleviates acute brain injury via reducing apoptosis and oxidative stress in a rat experimental subarachnoid hemorrhage model. Neurosci Lett. 2015;600:238-43. doi: 10.1016/j.neulet.2015.06.023. [PubMed: 26101829].

33. Robertson CL, Fidan E, Stanley RM, Noje C, Bayir H. Progesterone for neuroprotection in pediatric traumatic brain injury. Pediatr Crit Care Med. 2015;16(3):236-44. doi: 10.1097/PCC.0000000000000323. [PubMed: 25581631]

34. Beauparlant $P$, Hiscott J. Biological and biochemical inhibitors of the NF-kappa B/Rel proteins and cytokine synthesis. Cytokine Growth Factor Rev. 1996;7(2):175-90. [PubMed: 8899295]. 